\title{
A giant tonsillolith
}

\author{
Sohit Kanotra · Sonika Kanotra · J. Paul
}

\begin{abstract}
Tonsilloliths or calculi of the tonsil are calcifications that form in the crypts of the palatine tonsil or around it. Small concretions are asymptomatic while large calcifications produce symptoms such as odynophygia, dysphagia and referred otalgia. We describe a case of a 24 years old female who presented with a six month history of mild throat discomfort and was found to have a large $(3.1 \times$ $2.7 \times 2.1 \mathrm{~cm}$ ) calculus in her left tonsil for which a tonsillectomy was done. This is one of the largest reported cases in the world. The authors stress that symptoms of tonsillolith are unrelated to its size. The pertinent literature has been reviewed.
\end{abstract}

Keywords Tonsillolith • Tonsillar concretions

S. Kanotra ${ }^{1}$ • S. Kanotra ${ }^{2}$ • J. Paul ${ }^{3}$

${ }^{1}$ Department of E.N.T., Govt. Medical College,

Srinagar, India

${ }^{2} \mathrm{~J} \& \mathrm{~K}$ Health Services, India

${ }^{3}$ Department of E.N.T., ASCOMS,

Jammu, India

S. Kanotra $(\bowtie)$

e-mail: sohit_kanotra@rediffmail.com

\section{Introduction}

The earliest known description of concretions in the oropharynx is thought to be recorded by Lang in 1560 [1]. Small calcified areas are not an uncommon finding on routine sectioning of the excised tonsils but the presence of a giant tonisllolith is a rarity, with only about 50 cases having been reported [2]. Most of the calculi are composed primarily of calcium carbonate and calcium phosphate but other minerals such as magnesium, sodium, silica, potassium, copper, almunium, iron, ammonia radicals have also been reported $[3,4,5]$. The mechanisum of formation of tonsilloliths is still a subject of debate. The commonest accepted hypothesis is that tonsilloliths form from retained caseous secretions in the tonsillar crypts in conjunction with filaments of leptothrix buccalis - a common oral saprophyte,sometimes in association with chronic purulent tonsillitis [6]. Tonsillolithiasis can occur at any age but is more frequent in adults than children with a mean age of about 50 years and with equal sex distribution. The symptoms are usually non-specific such as sore throat and referred otalgia. A foreign body sensation and halitosis may also be presenting symptoms. It is not unusual for tonsilloliths to be diagnosed on routine radiological studies. Large calculi are clinically seen as a hard mass in the tonsil. A lateral radiograph of the neck shows a radio-opaque mass overlapping the ramus of the mandible and this can be mistaken for a foreign body, displaced tooth or a calcified blood vessel [6]. CT findings may reveal nonspecific calcified image in the tonsillar zone [6] Treatment consists of surgical removal of the stone. Tonsillectomy is indicated if the calculi are embedded in the tonsillar tissue or when associated with chronic tonsillitis.

\section{Gase report}

A 27-year-old female presented with a history of mild left sided discomfort in the throat with occasional mild pain in the left ear on swallowing. The past history was 
insignificant for recurrent throat infections. Oral examination revealed the right tonsil to be normal but the left tonsil was enlarged and showed a large grayish white mass with a pitted rough surface embedded in the tonsillar tissue. On palpation the mass was stony hard and nontender. The rest of the ear, nose and throat examination did not reveal any abnormality. There was no cervical lymphadenopathy. A clinical diagnosis of a tonsillolith was made. An ultrasound examination of the submandibular salivary glands, gallbladder and kidneys did not reveal any evidence of lithiasis. An attempt to dislodge the stone from the tonsil under local anaesthesia was unsuccessful and hence the patient was subjected to left tonsillectomy. The postoperative period was uneventful.

The tonsillolith was removed form the tonsil. It was brownish white in colour with a pitted rough surface and measured $3.1 \times 2.7 \times 2.1 \mathrm{~cm}$ (Fig. 1). Microscopic examination of the tonsil showed presence of calcification, necrotic debris and 'ghost cells'.

\section{Discussion}

Tonsilloliths or calculi of the tonsil are aggregates of varying size and consistency which develop in the crypts of the palatine tonsil or around it. Large tonislloliths are relatively uncommon though small concretions are a common finding in tonsillectomy specimens [2]. We found a concretion in the left tonsil of a 55 years old female on C.T. scan of the neck performed for vague symptom of right-sided throat pain (Fig. 2). Tonsilloliths can occur at any age but are more frequent in adults than children (age range: 10-77 years; Mean 50 years) [2]. Mesolella et al [2] in their review of fifty cases of tonsilloliths reported till date found that $69.7 \%$ were located in the tonsillar tissue, $21.2 \%$ in the tonsillar fossa while in $9 \%$ the tonsilloliths were palatine in location. The only case of a calculus of the lingual tonsil has been described by Bando et al [18]. The size of the tonsilloliths ranges from a few millimeters to several centimeters with the largest described being $41 \times$ $21 \times 19 \mathrm{~mm}$ [8]. The commonest symptom is pain in throat, followed by swelling in the tonsillar fossa, dysphagia, odynophagia, otalgia, peritonsillar abscess, swelling in the submaxillary triangle and halitosis. In some young adults tonsillar concretions may be associated with presence of whitish expressible foul-smelling and foul-tasting cheesy lumps from the tonsil [1].

Tonsilloliths which are located deeply in the tonsil may present with unilateral tonsillar enlargement. Multiple tonsilloliths have also been described [17]. In $9 \%$ of patients, the tonsilloliths are asymptomatic with most of the asymptomatic lesions less than $21 \mathrm{~mm}$ in the largest dimension [2]. Right-sided lesions $(60 \%)$ are more common than the left sided. Only three cases of bilateral tonsilloliths have been reported [10] till date.

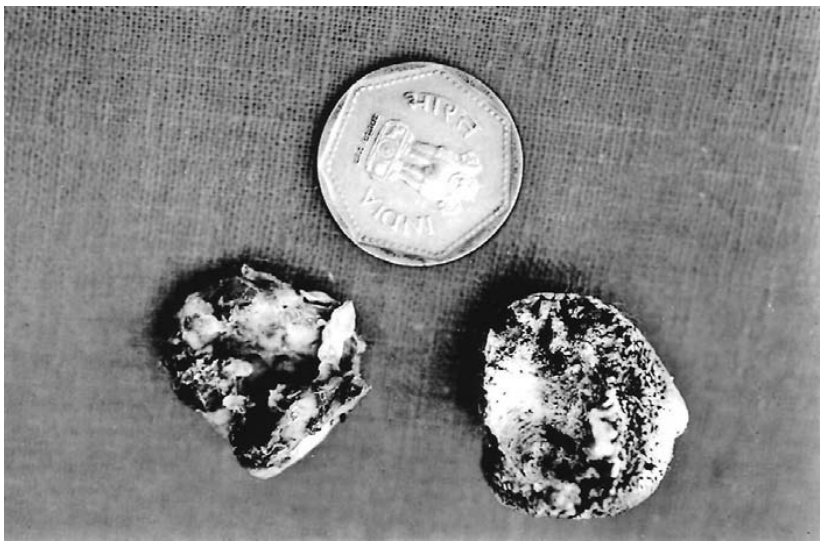

Fig. 1 Showing the removed tonsil and the tonsillolith

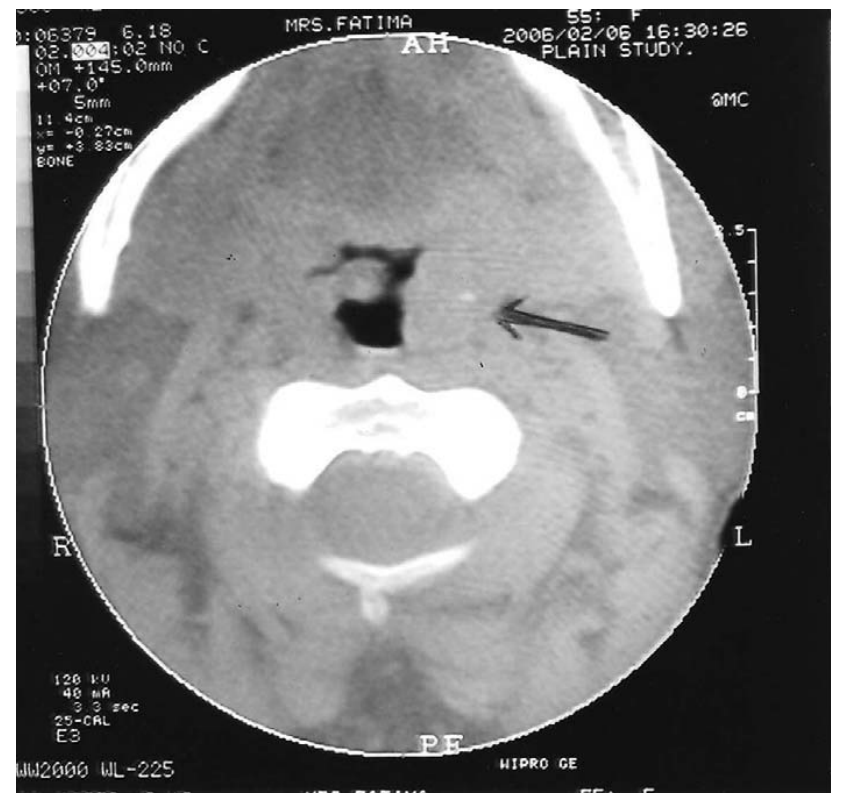

Fig. 2 CT Scan showing a small concretion (arrow) in the left tonsil of a patient who presented with vague right-sided throat pain

Clinically, the tonsillolith appears as a white or yellow-ish hard object within the tonsillar crypt. Tonsilloliths may be single or multiple and of variable shapes like round, oval, cylindrical, pyramidal or plurilobular [2]. The colour also varies from the commonest grayish yellow to dark gray, black or red brown [2]. Tonsilloliths simulating peritonsillar abscess [8] or malignancy [15] have been described.

The diagnosis can usually be easily made on clinical examination including palpation of the tonsil and for confirmation a lateral X-ray of the head will show the radio-opaque shadow. Tonsilloliths have been diagnosed on routine panoramic radiographs of the mandible. But in the absence of clinical examination, these radiographs may be misleading and give a false impression of an interosseous radio-opaque lesion such as a foreign body, odontoma, sclerosing osteitis, Garre's osteomyelitis, fibrous dysplasia, id- 
iopathic osteoslerosis, osteoma or a displaced tooth because of the superimposition of the tonsillolith on the mandibular ramus [16]. Tonsilloliths should also be differentiated form radio-opaque structures and lesions that occur in the soft tissues close to the jaws such a sialolith, a phlebolith, cysticercosis, calcified lymphnode, carotid artery arteriosclerosis, stylohyoid ligament mineralization and dystrophic calcifications in an acne scar [16], ectopic bone or cartilage, a large maxillary tuberosity or prominent hamulus of pterygoid [2]. Cases of pseudobilateral tonsilloliths have also been described in which a unilateral tonsillolith gave a false impression of a bilateral tonsillolith on lateral radiograph of the neck because of superimposition of a lesion involving one side of the jaw which created a ghost or a pseudoimage on the contralateral side [9]. Computed tomography may reveal nonspecific calcified image in the tonsillar zone and is not helpful in reaching a differential diagnosis [6].

The etiopathogenesis of tonsilloliths, is still uncertain. It is postulated that chronic tonsillitis associated with repeated episodes of inflammation produce fibrosis of the openings of the tonsillar crypts followed by accumulation of bacterial and epithelial debris in these crypts leading to the formation of retention cysts. Calcification occurs subsequent to the deposition of inorganic salts following which gradual enlargement of the concretion takes place [12]. The tonsilloliths derive their phosphates and carbonate of lime and magnesia from saliva secreted by the major salivary glands. However, this hypothesis cannot explain the existence of calculi in the peritonsillar zones and also in cases where prior tonsillectomy has been done. For this, some authors [3] have suggested that tonsillolith results from stasis of saliva in the efferent ducts of the minor salivary glands secondary to mechanical obstruction arising from post-tonsillectomy scars or chronic inflammation. This hypothesis is supported by the histological examination of the tissue excised from around the tonsillolith which revealed salivary gland lobuli with efferent ducts surrounded by lymphoid tissue in two cases [3]. Calcification of the peritonsillar abscess and existence of ectopic tonsillar tissue are other mechanisms by which peritonsillar stones can form. The association of tonsillolith with kidney stone [13], gall stones [14], and wharton's duct stones in 3\% of the cases [3] suggests that tonsillolithiasis could be a part of the lithogenic diathesis.

A mineralogical analysis of the tonsillolith reveals primarily carbonates and / or phosphates of calcium but, other minerals like magnesium, sodium, silica, potassium, ammonium radicals, copper, aluminum, iron have also been reported [2]. Tsuneishi et al [11] have described the composition of the bacterial flora in tonsilloliths using culture dependent molecular methods and scanning electron microscopy. Anaerobic bacteria detected in tonsilloliths belong to the genera Eubacterium, Fousobacterium, Megasphaera, Porphyromonas, Prevotella, Selenomonas and Tannerella.
All these anaerobes are associated with production of volatile sulphur compounds and this supports the tonsillolith as a cause of halitosis [11].

Regarding management, the tonsillolith can usually be removed by enucleation or curettage under local anaesthesia [2]. Larger lesions may require local excision and tonsillectomy is indicated in patients with chronic tonsillitis. The case under review underwent tonsillectomy because the giant tonsillolith was embedded in the tonsillar tissue. A review of literature shows that tonsilloliths more than two cm. in largest dimension were usually associated with significant symptoms. However our patient despite presence of a large tonsillolith presented with only a mild discomfort. Thus we infer that the symptoms of tonsillolith are independent of its size and even larger lesions may have minimum symptoms.

\section{References}

1. Pruet CW, Duplan DA (1987) Tonsil concretions and tonsilloliths. Otolaryngol Clin North Am 20:305-309

2. Mesolella M, Cimmino M, Martino DM et al (2004) Tonsillolith - Case report and review of the literature Acta Otorhinolaryngol Ital 24:302-307

3. Cooper MM, Steinberg JJ, Lastra $\mathrm{M}$ and Antopol S (1983) Tonsillar calculi. Report of a case and review of the literature. Oral Surg Oral Med Oral Pathol 55: 239-243

4. Heppt W, Schmidt ST, Amstutz GC, Maier H (1989) Tonsillolith: clinical picture and mineralogic analysis. HNO 37 : 438-439

5. Castellano M, Marcolli G (1996) Giant calculi of the Tonsil, Simulating a neoplasm. Minerva Med 57:1686-1688

6. Silvestre-Donat FJ, Pla-Mochali A, Estelles Ferriol E et al (2005) Giant tonsillolith: Report of a case. Med Oral Patol Oral Cir Bucal 10:239-242

7. Jones JW (1996) A tonsillolith Br Dent J 180: 128-130

8. Modrzynski M, Wrobel B, Zawisza E (2001) Giant tonsillolith simulating peritonsillar abscess. Pol Merkuriusz Lek 11 (65):432-433

9. Ram S, Siar CH, Ismail SM and Prepageran N (2004) Pseudobilateral tonsilloliths: a case report and review of the literature. Oral Surgery, Oral Medicine, Oral Pathology, Oral Radiology and Endodontics 98(1):110-114

10. Mosca RC, Cabral MVG, Mantesso A (2006) Bilateral tonsilloliths in a 77 year old white man with edentulous jaws. A case report. Oral Radiology 22:34-36

11. Tusuneishi M, Yamamoto T, Kokeguchi S, Tamaki N, Fukvi K, Watanabe T (2006) Composition of bacterial flora in tonsillolithiasis. Microbes Infect 8(9-10): 2384-2389

12. Paparella MM, Schumrick DA (1991) Otolaryngology (Vol III Head \& Neck), 3rd edition, Philadelphia. W.B. Saunders p. 2141

13. Neshat K, Penna KJ, Shah DH (2001) Tonsillolith : a case report. J Oral Mixillofac Surg 59:692-693

14. Swain HI (1920) Recurrent Calculus of the Tonsil-Report of a case. Ann Otol Rhinol Laryngol 29:73-78 
Indian J. Otolaryngol. Head Neck Surg.

15. Padmanabhan TK, Chandra Dutt GS, Vasudevan DM, Vijaykumar (1984) Giant Tonsillolith, simulating tumour of the tonsil - a case report. Indian J Cancer 21:90-91

16. Sezer B, Tugsel Z, Bilgen C (2003) An unusual Tonsillolith. Oral Surg Oral Med Oral Pathol. Oral Radiol Endol 95 (4): $471-473$
17. Dogru H, Tuz M, Aycicek A (2001) Unusual Multiple Giant Tonsillolith. Oto-Rhino-Laryngologia Nova 11: 319-321

18. Bando $\mathrm{H}$, Uno $\mathrm{T}$, Nin $\mathrm{F}$, Tei $\mathrm{K}$, Shinomiya $\mathrm{T}$ and Hisa $\mathrm{Y}$ (2003) A case of Calculus of the Lingual Tonsil. Practica oto-rhino-laryngologica 97 (7) 